\title{
Yoga and meditation: integrating mind-body medicine into a workplace wellness program. Police agency organizational and implementary considerations
}

\section{Introduction}

Existing research on stress among police officers shows the presence of a myriad of uniform stressors across job roles shaped by the unique nature of criminal justice work..$^{1,2}$ Carefully designed intervention is desperately needed to address the most aggravating stressors plaguing police officers. The following paper presents and discusses the recommended steps for implementing a stress reducing innovative Mind-Body Medicine Workplace Wellness Program within a police department. Workplace wellness is a focus of import for organizations, supernumerary it is even more important in criminal justice work environments where officers literally hold lives in their hands. This innovative activity can be offered to police officers, utilizing interagency collaboration, at a low cost to the organization. The new program parallels popular interest in the mind-body connection and emphasizes the influence of yoga and meditation while simultaneously providing officers with the opportunity to fully benefit from mind-body components of a workplace wellness program.

\section{Abridged review of literature}

When compared to society at large, police officers have particularly stressful lifestyles, placing them at greater risk of a multitude of stress related diseases in addition to overall mortality and decreased life expectancy. ${ }^{1,3-5}$ "Developing a comprehensive list of every stressor potentially confronted by policing officers would be an impossible task". ${ }^{1}$ The number of years of service in police officer duties is further associated with cardiovascular disease risk, obesity, diabetes, stress related illness, post-traumatic stress disorder (PTSD), depression, aggression disorders, high blood pressure, sleep disorders, increased use of tobacco, a conundrum of behavioral and mental health issues, physical inactivity, and physical fitness decline. ${ }^{2-4,6}$

The stressors that police officers face in their daily work are eminently severe. ${ }^{1,7,8}$ One of the many strains described by Lipsky ${ }^{7}$ in his 1980 groundbreaking book on street-level bureaucracy, is inadequate departmental resources. Police forces are perpetually understaffed, particularly as perceptions of crime and demands for civic order increase. Insufficient organizational resources increase the pressures on these officers to make quick decisions about citizens without adequate information. ${ }^{1}$ Police officers are widely thought to lack sufficient resources to accomplish the dangerous work of protecting and serving communities. This kind of strain and distress readily observed in street level law enforcement is causing a disturbing trend and alarming decline of police officer health.

\section{Mind-body medicine for police officer health}

Mind-body medicine is a revolutionary approach emerging to represent a broader healing paradigm of medicine than the biomedical model alone. ${ }^{9,10}$ This type of medicine is patient centered, healing oriented, and involves a shift from focusing on only physical illness to focusing on the physical health and mental health of the patient. ${ }^{9,11}$ The police officers in Dr. Maran, Dr. Zedda, and Dr. Varetto's 2018 mind-body medicine study expressed having improved
Volume 12 Issue 2 - 2019

\author{
Robelyn A Garcia ${ }^{1,2}$ \\ 'Arizona State University, USA \\ ${ }^{2} \mathrm{Harvard}$ University, USA
}

Correspondence: Correspondence: Robelyn A Garcia,Arizona State University, USA, Email Dr.RobelynGarcia@asu.edu

Received: March 01, 2019 | Published: April 16, 2019

overall physical well-being, improved mental health, improved use of adaptive coping strategies, and decreased maladaptive coping strategies. Mind-body medicine includes intervention strategies and therapeutic approaches that promote health including but not limited to yoga, meditation, Pilates, tai chi, relaxation therapy, clinical and applied hypnosis, guided and visual imagery, biofeedback, prayer, qi gong, metaphysical healing, metaphysical counseling, cognitivebehavioral therapy, spirituality, spiritual counseling and autogenic training. ${ }^{9-12}$ For the purposes of this paper and the police officer Workplace Wellness Program, yoga and meditation will be the mindbody medicine modalities prescribed, implemented and utilized.

\section{Yoga and meditation for police officers}

Empirical evidence continues to accumulate revealing that yoga and meditation are proving notably useful in reducing stress, physical disorders and mental illness for police officers. ${ }^{6,11-14}$ Meditation and mindfulness training can play a significant role in reducing chronic stress and providing coping tools for the daily rigors police officers face. ${ }^{15}$ Findings have also confirmed both physical and mind-body exercises for police officers "affected, in participants, the perceived distress, thereby increasing the perception of wellbeing". ${ }^{8}$ This research further confirms that yoga and meditation can effectively reduce the risk of chronic disease, a consequence of persistent exposure to law enforcement officer work distress. ${ }^{8,11}$ Another large-scale study, with over 1,000 participants, reported that yoga and meditation provide statistically significant results for treating symptoms of stress disorders. ${ }^{11}$ Meditation and yoga-based approaches allow for a variety of treatment options, increase patient choice, and address several domains of stress illness.

In addition to the benefits typically associated with yoga (improved strength, flexibility and breathing) a yoga routine often provides the following benefits for those struggling with anxiety and stress: reduced pain, reduced aggression, reduced obsessions, reduced PMS symptoms, decreased depression and anxiety symptoms, decreased self-stimulatory behaviors, increased control of emotions, and the joy of sharing class with others and making new friends. ${ }^{16}$ Yoga's physiological and psychological processes that produce so many positive benefits are achieved through respiratory manipulation intermediated by breathing techniques, postures, and cognitive controls of relaxation and meditation. ${ }^{16}$ 


\section{Police officer yoga}

Generally, Westerners are most familiar with Hatha yoga because it deals with the overall health of the physical body, refers to the practice of physical postures and is supported by empirical evidence. ${ }^{17}$ "The original purpose of Hatha Yoga was to give people who were more physically oriented an opportunity to experience Union with God through a combination of postures, breathing exercises, stretching, ect. However, it caught on in the United States for its physical benefits". ${ }^{18}$ As such, the majority of yoga practiced in the United States is technically and commonly known as Hatha. Hatha yoga is an increasingly popular activity, perhaps due to its beginner-friendly style, stress reduction qualities, and association with a healthier body. "While, indeed, the body can be healthier through its practice, the main concern of Hatha Yoga is utilizing physical postures and breathing exercises to stimulate the psycho-physical chemistry, in order to awaken what are called the chakras". ${ }^{17}$ Traditionally, the purpose of beginner Hatha yoga postures, breathing, and deep relaxation is to restore balance in your chakras (the body's energy centers) and prepare a person's mind and body for meditation, the final component of yoga. Therefore, Hatha yoga is an excellent choice for an American police department wellness program. The police officer Hatha yoga program will begin with twenty minutes of novice postures provided in An Introduction to Yoga: Improve your strength, balance, flexibility, and well-being. A Harvard Medical School Special Health Report (Harvard Health, 2016) and progress at the certified instructor's discretion.

\section{Police officer meditation}

In a police officer's stressful world, they have an evergrowing need to learn the practice of meditation. "For neophytes, it is generally advisable to start with very light forms of Western Meditation". ${ }^{18 \text { "You }}$ may practice meditation either sitting up or lying down ... Beginners should practice in a sitting position". Basic breathing meditation is a light beginner form of meditation done in a variety of elementary sitting positions (Harvard Health, 2016), thus will be utilized for the police officer meditation component of the workplace wellness program. The basic breathing meditation practice also uses the basic hand position of gyan mudra. Gyan mudra, simply involves lightly touching the tip of your thumb and forefinger, with the remaining fingers of your hand relaxed, gently extended, with palms facing upward and resting in your lap (Harvard Health, 2016). Just as the police officer Hatha yoga component, the meditation component will begin with novice practices and progress at the certified instructor's discretion. It is of import to notate that the meditation will be integrated into Hatha yoga, immediately follow the yoga postures and last for ten minutes as explained in Table 1.

Table I Police Officer Yoga and Meditation Program

\section{Police officer yoga and meditation program three step designs}

Step 1: Following an orientation to the new program, the police officers will fill out and sign a confidential physical activity readiness questionnaire (PAR-Q), consent form, personal information form, incentive form and a workplace wellness exercise adherence contract prior to participating in any of the yoga and meditation activities. Additionally, the officers will be provided Harvard University beginner Hatha yoga guides and University of Sedona beginner meditation handbooks which will describe and illustrate the activities they will be performing in their new program. ${ }^{12}$

Step 2: Upon completion of the orientation and baseline forms, police officers will begin the three times per week yoga and meditation exercises led by highly qualified interagency health professionals. The Mind-Body Medicine "Yoga and Meditation" program will include the following:

\section{A. Warm-up}

Flexibility Exercises - Stretch every day before Yoga and Meditation (e.g., stretch and hold each flexibility exercise for at least 20 seconds as demonstrated by instructor).

Ten Flexibility Exercises for Warm-up \& Cool-down are; 1). Inverted Hurdler 2). Biceps Stretch 3). Butterfly Stretch 4). Triceps Stretch 5). Pretzel Stretch 6). Shoulder Cross Stretch 7). Straddle Stretch 8). Chest Pectorals Stretch 9). Quadriceps Stretch and 10). Calf Stretch ${ }^{19}$

\section{B. Mind-Body Medicine Activity}

Yoga and Meditation Workplace Wellness Component. Participants complete 30 minutes of Yoga and Meditation with a frequency of three times per week.

1. Police officer Hatha yoga exercise prescription: twenty minutes of beginner postures as aforementioned, outlined and illustrated in An Introduction to Yoga: Improve your strength, balance, flexibility, and well-being. A Harvard Medical School Special Health Report.

2. Police officer basic breathing meditation exercise prescription: ten minutesof beginner meditation practice as aforementioned, outlined and described in the founder of The University of Metaphysics book Meditation Dynamics. ${ }^{12}$

\section{Cool-down}

Flexibility Exercises - Stretch every day after Mind-Body Medicine Activity, when officer's muscles are warm and more compliant.

1. Same Ten Flexibility Exercises as prescribed for Warm-up to flow as part of the natural evolutionary process of the end of a yoga-meditation session.

Step 3: Weekly police officer confidential progress examination, incentive analysis, interagency public health professional feedback and evaluation will be provided by HIPAA compliant telephone calls, text messages, and online interaction and or in person.

\section{Organizational change and organizational structure}

The most successful workplace wellness programs for criminal justice agencies require high level management capable of instituting transformational organizational change. ${ }^{2}$ Several approved structural changes will be necessary for this mind-body medicine program to be implemented successfully. It is imperative that any new duties in the organizational structure be divided up fairly and coordinated justifiably because it can affect job satisfaction and organizational commitment. ${ }^{20}$ 
The Transtheoretical Model (TTM), also called the Stages of Change Model is not a theory but a model of six stages of change that can be applied to various stages of the proposed Mind-Body Medicine Workplace Wellness Program. ${ }^{21}$ "The well-established TTM model is utilized successfully by behavioral healthcare practitioners and fitness and wellness experts". ${ }^{22}$

Selected models, organizational structure and organizational theories can validate the need for a mind-body medicine workplace wellness program while theories of organizational change can support the execution of the innovation. ${ }^{14}$ The theory of organizational planned change will guide the police agency and the local affiliated public health agency throughout the integration and implementation of the Mind-Body Medicine Workplace Wellness Program. This will be an interagency planned change that both interrelated organizations go through together toward the common goal of improved police officer health. Each cooperative step facilitated toward this goal is preventive in nature rather than reactive when driven by the planned change theory. ${ }^{2}$

\section{Interagency collaboration}

Interagency collaboration between the police department and the public health department is essential to building a productive new workplace wellness program. The new workplace wellness administrative duties will be provided by police departmental staff while the yoga and meditation program instructional, monitoring and feedback duties will be provided by experienced behavioral health consultants and yoga-meditation practitioners from the affiliated public health department. Monitoring officers' participation and providing feedback for each police officer shall be a key component of the new wellness program..$^{22}$ The Mind-Body Medicine Workplace Wellness Program is a new mandatory strategic activity for all rookie police officers with a gradual step by step adaptation among longtime employees. The program will be partially modeled after other successful employee wellness programs with a goal of creating a platform of sophisticated and fulfilling incentives, reducing officer stress and saving lives. ${ }^{23} \mathrm{~A}$ common procedure when an organization begins a new venture is to mimic the actions of other organizations based on the belief that the protocols of the model organizations have proven successful. ${ }^{1}$

\section{Organizational theory}

Certain theoretical approaches are needed to help guide the implementation of a mind-body medicine program of this nature within a police department. Organizational theories will serve as one of the driving forces behind the implementation of this much needed innovative program. Specifically, the open systems contingency theory and the human relations theory. The contingency theory will be most effective because open systems theories are modern ways of viewing the importance of the ever-changing police force environment. While contingency theory is not the only open systems theory of organizations, it is the most commonly one applied to criminal justice organizations. Contingency theory has immense instinctive appeal within criminal justice organizations because organizational leadership can rationally construct successful departmental policies and adapt them as needed. "Among the contemporary open systems theories, contingency theory has garnered the most interest within the criminal justice discipline". ${ }^{4}$ Following the contingency theory affords good judgement when implementing a new employee wellness program for many different types of police departments. Further, the contingency theory offers "the best explanation for organizational structures and practices, suggesting that the ideal arrangement depends on or is contingent on environmental characteristics, organizational size, and other determinants". ${ }^{4}$ Department performance and organizational structure and practices are factors that can be adapted in contingency theory to increase an organization's performance as leaders try to steer their organizations toward the successful accomplishment of their goals. Although the theory has been criticized for a possible endless list of contingencies, there are many proponents of the theory for readily adapting to the many faces of the police force.

The human relations theory addresses one of the shortcomings of classical organizational theories, the neglect of the worker. This theory logically emphasizes the importance of each individual police officer's health. The research that solidified human relations thinking initially commenced as a series of scientific management-oriented studies called the Hawthorne studies. The researchers established the Hawthorne effect, worker productivity increasing because of the special treatment and attention workers are given. Unlike scientific management, bureaucracy, or administrative management theory, human relations theory paid greater attention to the needs of every worker, viewing each employee as one individual with individual needs. ${ }^{1}$ With a concern for each individual police officer's health, their behavior and informal structures, productive participation in the workplace wellness program will assuredly increase.

\section{Conclusion}

Research shows that because of the violence, high-risk workplace and demands of the job, police officers have some of the highest levels of comorbid health issues and stress among all occupations. ${ }^{24,25}$ Criminologists and social scientists are encouraging law enforcement brass to explore and understand evidence-based solutions that have been proven successful, practical, affordable, and accessible. "Recent calls for police to focus more on integrating research into practice require paying closer attention to how receptive frontline practitioners are to using research" ${ }^{26-31}$ Applying this knowledge to criminal justice wellness programs will produce more effective law enforcement by cultivating resilience, fostering civility and improving health among police officers. The importance of police officers' health is not only vital to the officers themselves, it is vital to the health of communities as a social responsibility. The proposed Mind-Body Medicine Workplace Wellness Program is necessary for police departments to create a healthy and resilient workforce. "This requires recognition that reducing the harms associated with stressors takes more than addressing them after they have already emerged. Organizations must be willing to alter from within, tackling some of the chronic stressors that are salient to many officers". ${ }^{1}$ By adhering to the execution of this plan, a higher level of cost-effective stress management integration can be achieved by investing in and incorporating Mind-Body Medicine into the workplace wellness program. Furthermore, depending on the circumstances and as needed, policies will be considered and reevaluated during each fiscal year with possible expansion such as increasing incentives and or expanding Mind-Body Medicine services to meet the challenges of the police force.

\section{Acknowledgments}

The author would like to thank Arizona State University, Harvard University, University of Sedona and The University of Metaphysics for the resources utilized to develop this plan. The author also acknowledges Tim Geiger for his continued support and expert 
advice. The author shows immense gratitude to the aforementioned entities, although they may or may not agree with the conclusions and interpretations of this article.

\section{Conflicts of interest}

Author declares that there is no conflict of interest.

\section{References}

1. Giblin MJ. Leadership and management in police organizations. USA: Sage publications; 2019.

2. Williams J, Ramsey V. The Need for Law Enforcement Wellness Interventions: A Critical Review. The Sport Journal. 2017;2.

3. Christopher MS, Hunsinger M, Goerling LRJ, et al. Mindfulness-based resilience training to reduce health risk, stress reactivity, and aggression among law enforcement officers: A feasibility and preliminary efficacy trial. Psychiatry Research. 264:104-115.

4. Giblin MJ. Organization and management in the criminal justice system: A text/reader. Thousand Oaks, CA: Sage Publications; 2016. p. 672.

5. MacMillan F, Karamacoska D, El Masri A, et al. A systematic review of health promotion intervention studies in the police force: study characteristics, intervention design and impacts on health. Occup Environ Med. 74(12):913-923.

6. Lipsky M. Street-Level Bureaucracy, Dilemmas of the Individual in Public Services, 30th Anniversary Expanded Edition. Russell Sage Foundation. 2010

7. Acquadro Maran D, Zedda M, Varetto A. Physical Practice and Wellness Courses Reduce Distress and Improve Wellbeing in Police Officers. Int J Environ Res Public Health. 2018;15(4):578.

8. Garcia R. Integrative Mind-Body Medicine as a Treatment for Psychophysiologic Disorders Utilizing the Seven Keys to Treating Stress Illness. International Journal of Complementary and Alternative Medicine. 2015;1(3):00017.

9. Garcia R. Consumer Health Awareness: A Guide to Intelligent Decisions for Selecting Integrative Holistic Medicine. Adding Complementary and Alternative Medicine to Science Based Healthcare. 2018.

10. Gallegos AM, Crean HF, Pigeon WR, et al. Meditation and yoga for posttraumatic stress disorder: A meta-analytic review of randomized controlled trials. Clin Psychol Rev. 2017;58:115-124.

11. Masters PL. Meditation dynamics: For self-realization, serenity, intuitive guidance, success, and mystical illumination. Sedona, AZ: University of Sedona Publishing; 2018.

12. Dwivedi U, Kumari S, Akhilesh KB, et al. Well-being at workplace through mindfulness: Influence of Yoga practice on positive affect and aggression. Ayu. 2015;36(4):375-379.

13. Francis A, Beemer R. How does yoga reduce stress? Embodied cognition and emotion highlight the influence of the musculoskeletal system. Complementary Therapies in Medicine. 2019;43:170-175.

14. Sutton H. Mindfulness-based training leads to improved health for law enforcement. Campus Security Report. 2018;15(8):9.
15. Radhakrishna S, Nagarathna R, Nagendra HR. Integrated approach to yoga therapy \& autism spectrum disorders. Journal of Ayurveda and Integrative Medicine. 2010;1(2):120-124.

16. Masters PL. University of Metaphysics Master's Degree Curriculum Modules. $1^{\text {st }}$ edn. Sedona, AZ: University of Sedona Publishing; 2014.

17. Masters PL. University of Metaphysics Master's Degree Curriculum Modules. $1^{\text {st }}$ edn. Module 16. Sedona, AZ: University of Sedona Publishing.

18. Garcia RA. Does online "Working out Work" as a treatment and prevention fordepression in older adults? An analysis of a prescribed and monitored exercise program administered via the Internet for senior adults. Tempe, Arizona: Arizona State University. 2011.

19. Huang H, Mattke S, Batorsky B, et al. Incentives, Program Configuration, and Employee Uptake of Workplace Wellness Programs. Journal of Occupational and Environmental Medicine. 2016;58(1):30-34.

20. LaMorte WW. Behavioral Change Models. USA: Boston University School of Public Health; 2018.

21. Garcia R, Benavidez D. Transtheoretical Model Key Constructs Applied to the Intervention \& Treatment of Weight Cycling \& Yoyo Dieting Cognitive-Affective Bases of Health for Weight Management. International Journal of Complementaryand Alternative Medicine. 2016;3(3):1-4.

22. Maricopa County Government. Maricopa County's Wellness Works Stay Well Be Well Incentive Program: Plan Year 2018-2019. 2017.

23. Jeter PE, Cronin S, Khalsa SB. Evaluation of the benefits of a kripalu yoga Program for police academy trainees: a pilot study. International Journal of YogaTherapy. 2013;23(1):24-30.

24. Joyce S, Shand F, Bryant RA, et al. Mindfulness-Based Resilience Training in the Workplace: Pilot Study of the Internet-Based Resilience@ Work (RAW) Mindfulness Program. Journal of Medical Internet Research. 2018;20(9):e10326.

25. Telep CW. Police officer receptivity to research and evidence-based policing:examining variability within and across agencies. Crime \& Delinquency. 2016;63(8):976-999.

26. Benavidez D. Six exercises all senior adults should be doing regularly. International Journal of Complementary and Alternative Medicine. 2018;11(1):56-57.

27. Garcia RA. Population health telehealth intervention: Medical research for treating comorbid clinical obesity and depression in geriatric patients. Part one: Review of tele-medicine scientific research. Research in Medical \& Engineering Sciences. 2017;1(5):1-4.

28. Maciel RRBT, Chiavegato LD, Marin LS, et al. Development of an e-health education program at the workplace using formative research - Technologies for improving quality of life. Evaluation and Program Planning. 2019;73:129-137.

29. Staywell. Client Success Story: Maricopa County.

30. Rakel D. Integrative Medicine $4^{\text {th }}$ edn. New York, USA: Saunders; 2017. 